\title{
Underlying Mechanisms for Distant Metastasis - Molecular Biology
}

\author{
Eva Pachmayr ${ }^{a, b} \quad$ Christoph Treese ${ }^{a-d} \quad$ Ulrike Stein ${ }^{a, b, e}$ \\ ${ }^{a}$ Experimental and Clinical Research Center, Charité - Universitätsmedizin Berlin, Berlin, Germany; \\ ${ }^{\mathrm{b}}$ Max-Delbrück-Center for Molecular Medicine, Berlin, Germany; \\ 'Department of Gastroenterology, Infectious Diseases, Rheumatology, Charité - Universitätsmedizin Berlin, Campus Benjamin Franklin, \\ Berlin, Germany; \\ dBerlin Institute of Health (BIH), Berlin, Germany; \\ ${ }^{\mathrm{e}}$ German Cancer Consortium (DKTK), Heidelberg, Germany
}

\section{Keywords}

Metastasis - Molecular mechanism - Cancer therapy

\section{Summary}

Background: The formation of distant metastases constitutes a complex process with a variety of different genes and pathways involved. To improve patient survival, it is necessary to understand the underlying mechanisms of metastasis to allow for targeted intervention. Methods: This review provides an overview of the general concepts of metastasis, focusing on the most important genes and pathways involved and on interventional strategies. Results: Cancer cells undergo different steps to form metastasis: most prominently, local invasion, intravasation, survival in the circulation, arrest at a distant organ site and extravasation, micrometastasis formation, and metastatic colonization. In order to pass these steps, different molecular pathways are of major importance: EGF/RAS/ RAF/MEK/ERK, PI3K/Akt/mTOR, HGF/Met, Wnt/B-catenin, and VEGF signaling. The HGF/Met regulator MACC1 and the Wnt signaling target S100A4 have been shown to play a major role in the metastatic process. Each gene and pathway provides an opportunity for therapeutic intervention. Conclusion: Since metastasis represents a highly limiting factor in cancer therapy causing $90 \%$ of cancer deaths, it is imperative to reveal the underlying mechanisms. This is fundamental for uncovering prognostic markers and new targeted therapy options.

Eva Pachmayr and Christoph Treese contributed equally to the manuscript.

\section{Concepts of Metastasis}

In 1889, the English surgeon Stephen Paget illustrated his theory on metastasis with the sentence 'When a plant goes to seed, its seeds are carried in all directions, but they can only live and grow if they fall on congenial soil'. He based this 'seed and soil' hypothesis on autopsy records where he detected a discrepancy between the blood supply and frequency of metastasis in specific organs. He concluded that the development of metastasis depends on distinctive features of the tumor cells as well as the specific target organs $[1,2]$. This concept replaced the mechanistic hypothesis of Rudolf Virchow who considered metastasis as the arrest of tumor cell emboli in the vasculature [2]. Nowadays, metastasis is understood as a complex process of molecular and biochemical events performed by multiple actors. The concept of a 'homogenous seed' has been replaced by a heterogeneous hierarchically organized system of tumorigenic cancer stem cells and their non-tumorigenic progeny [3]. Cancer stem cells are now regarded to be the major driver in metastasis development. In addition, the idea of a sequential development of a cancer from a single primary tumor to the subsequent spread to distant sites was abandoned in the last years and replaced by a model of a simultaneous progression towards metastatic tumor disease. The currently favored model describes the evolution of systemic tumor disease as a parallel development of primary tumor and distant metastasis caused by heterogeneous tumor subpopulations [4].

To understand the cellular and molecular basis of metastasis, the most acknowledged approach is the concept of the invasionmetastasis cascade proposed by Isaiah J. Fidler in 2003 and subsequently adapted by Scott Valastyan in $2011[5,6]$. The authors distinguish 6 steps in the process from primary local tumor to distant

\section{KARGER}

() 2017 S. Karger GmbH, Freiburg

Fax +497614520714 


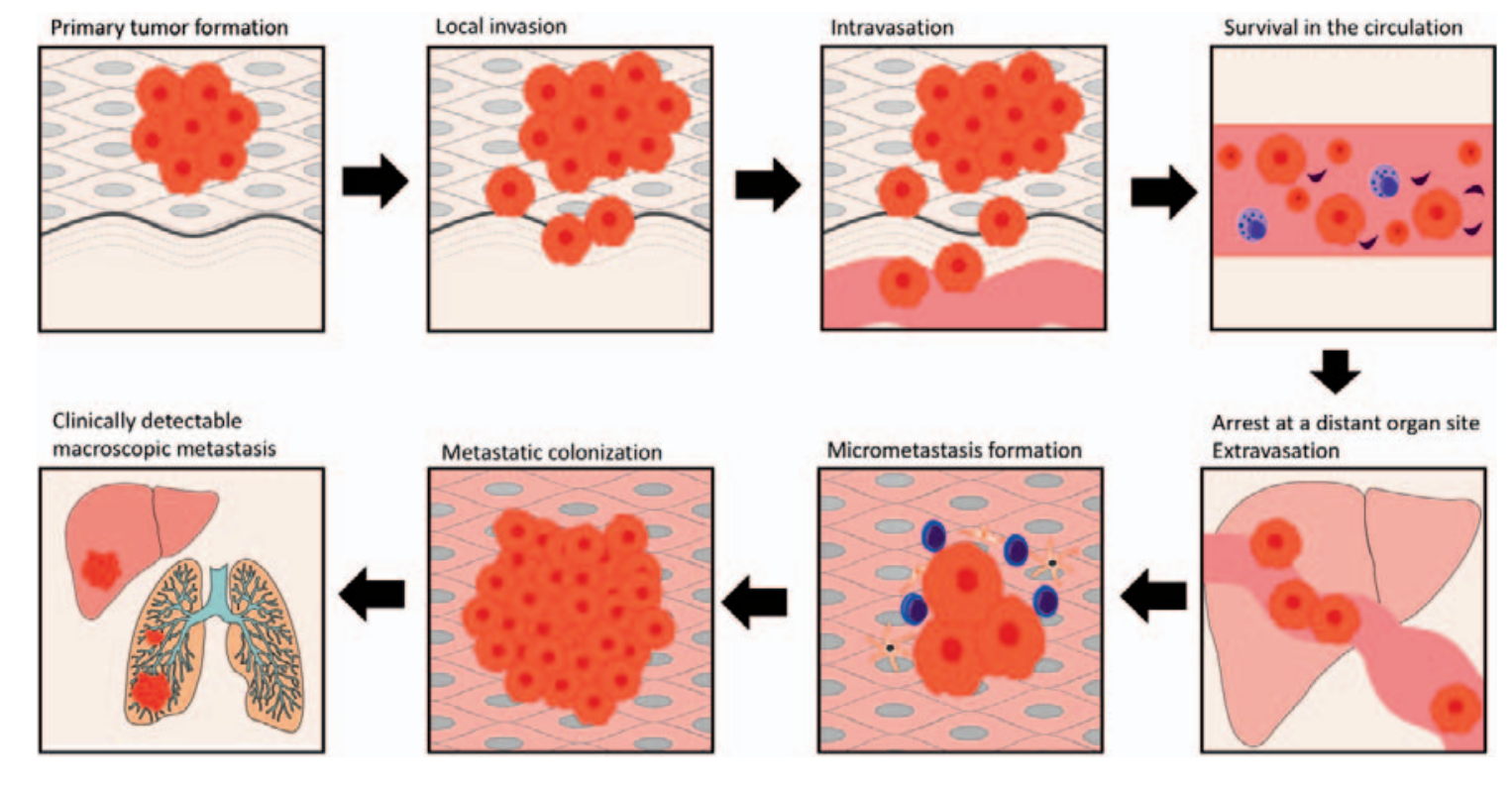

Fig. 1. Invasionmetastasis cascade (modified from Valastyan et al. [6]).

metastasis: i) local invasion, ii) intravasation, iii) survival in the circulation, iv) arrest at distant organ site and extravasation, v) micrometastasis formation, and vi) metastatic colonization (fig. 1).

\section{Local Invasion}

Tumor spread starts with the migration of tumor cells from the confined primary tumor into the adjacent tissue. Clinically, this represents the step from an intraepithelial carcinoma Tis to a T1 tumor stage. Tumor cells cross the basement membrane and the lamina propria and invade the underlying connective tissue. Morphologically, the cells change from highly differentiated to undifferentiated. Unlike normal epithelial cells, which undergo apoptosis upon losing contact to their native extracellular matrix, tumor cells develop mechanisms to detach from the primary tumor [7]. The transformation enabling tumor cells to accomplish migration and invasion is called epithelial-mesenchymal transition (EMT) [7]. During this process, E-cadherin, a key protein for epithelial cell-cell adhesion, is downregulated by transcription factors like Slug, Snail, Twist and ZEB-1/-2, rendering the epithelium more permeable [8]. To be able to migrate, tumor cells must respond to migratory stimuli and acquire morphological protrusions. These membrane extensions contain actin. The leading cell front attaches to the extracellular matrix (ECM) serving as a traction site. The formation of actin filament stress fibers precedes the formation of focal adhesion [9].

After detachment from the primary tumor, EMT, migration, and invasion through the basement membrane, tumor cells can directly invade by degrading the ECM by secretion of proteases like matrix metalloproteinase (MMP)-1, -2, and - 9 and activation of the proteolytic urokinase-type plasminogen activator system (uPA/uPAR) [10].

Usually, stroma reacts to tumor invasion with inflammation, confronting tumor cells with various cell types including mac- rophages, neutrophils, dendritic cells, and immune cells like T- and B-lymphocytes. In this milieu, the different cells shape the tumor microenvironment and produce a complex mixture of cytokines, chemokines, growth factors, and inflammatory and matrix modeling enzymes [11]. Cytotoxic CD8-positive T-lymphocytes, for example, control the elimination of tumor cells, and tumors with high CD8 infiltration are associated with low metastasis and good prognosis, whereas CD4-positive lymphocytes promote tumor invasion by stimulating tumor-associated macrophages to activate epidermal growth factor receptor (EGFR) signaling in tumor cells $[6,12]$.

\section{Intravasation}

The tumor cells enter the veins (V1) and the lymphatic vessel system (L1; TNM system). Both factors have remarkable prognostic relevance in gastrointestinal tumors [13]. For intravasation, tumor cells directly migrate into vessels. This seems to be caused by factors similar to those involved in local invasion: secretion of proteases like MMP-1, -2 and -9 and activation of uPA/uPAR [10]. Via neoangiogenesis, new vessels are formed, which allows growing tumors to gain access to more nutrients and oxygen [14]. This is accomplished by secreting angiogenic factors, most prominently the vascular endothelial growth factor (VEGF).

\section{Survival in the Circulation}

Blood is a hostile environment for circulating tumor cells (CTCs). Less than $1 \%$ of CTCs flowing in the blood every day will survive and have a chance to produce distant metastasis $[15,16]$. Killer factors in the circulation seem to be the physical shear forces in the blood stream and the surveillance by immune cells, particularly natural killer cells [17]. Tumor cells protect themselves from 
physical stress and immune surveillance by secreting substances like thrombin, cathepsin B, cancer procoagulant, and MMP-2/-14 with the consequence of platelets aggregating around the tumor cells, a process known as tumor cell-induced platelet aggregation. Additionally, this platelet 'coat' helps to facilitate extravasation and the arrest at distant organ sites [18].

\section{Arrest at Distant Organ Sites and Extravasation}

Aggregated CTCs form emboli that bind to the endothelium of the vessels in the target organ or might even obstruct them completely. For metastasis, CTCs have to leave the circulation, a step described as extravasation. This is achieved by secretion of factors that induce vascular hyperpermeability like protein angiopoietinlike-4 (Angptl4) and MMP-1/-2 [6].

Extravasation after embolization is not a mandatory process. Tumor cells seem to have a specific affinity to certain organs. One factor involved in this process might be the release of chemokines specific for each organ and the expression of appropriate chemokine receptors on the surface of the tumor that help tumor cells to target their specific soil. The best-known example is the expression of chemokine receptor 4 (CXCR4) in breast cancer. Tumors with CXCR4 expression migrate to organs that express high levels of its ligand CXCL12. CXCL12 is expressed in the common sites of metastasis for breast cancer: lung, liver, bone marrow, and brain [19]. CXCR4 is also expressed in some gastric, colorectal, and pancreatic carcinomas. Other liver-specific receptors in gastrointestinal cancer are CXCR1/-2 and CCR1/-6. The specificity of metastatic sites for each tumor entity is also called tissue tropism. The mechanisms of tissue tropism are currently not sufficiently understood, but in the daily clinical routine we are often confronted with this phenomenon: rectal cancer primarily disseminates into the lung while colon, gastric, or pancreatic cancers disseminate into the liver. There are also exceptional locations, for example the development of ovarian metastasis from signet ring cell carcinoma of the stomach, colon or appendix, also called Krukenberg tumors [17]. Tissue tropism not only helps to predict future metastatic sites, but might also be a target for future antimetastatic drug therapy.

\section{Micrometastasis Formation}

After extravasation, CTCs arrive at the target organ tissue and need to create specific conditions. Kaplan et al. [20] reported that the primary tumor releases growth factors into the circulation. These growth factors lead to an upregulation of VEGF-A, placental growth factor (PlGF), transforming growth factor- $\beta$ (TGF $\beta$ ), and inflammatory proteins S100A8/-9 at the future metastatic sites. Consequently, VEGF receptor (VEGFR) 1-positive bone marrowderived hematopoietic progenitor cells are recruited and the ECM is modulated at these sites. This already 'primed' tissue, which does not yet harbor tumor cells, provides the 'soil' for future metastasis and is called the premetastatic niche [21-23].

\section{Metastatic Colonization}

As the last step of the metastatic cascade, micrometastases have now spread to distant organs. After formation of undetectable micrometastases, the tumor cells have to proliferate to form large macroscopic metastases. This growth does not follow a strict temporal pattern since the type of quiescent tumor cells surviving at distant organ sites can also be present in the patient's bone marrow for several years. Only about $50 \%$ of these patients will develop detectable metastases [24]. This phenomenon is called metastatic latency and seems to be related to the phenomenon of tumor dormancy. A recently published work from Malladi et al. [25] hypothesizes metastatic latency to be controlled by autocrine Wnt inhibition.

\section{Genes and Pathways Involved in Metastasis and Concepts of Intervention}

To form metastasis, cancer cells undergo various steps from local invasion to metastatic formation. This process is driven by alterations in multiple genes and pathways. Below we give an introduction to the most prominent alterations and possibilities of intervention.

\section{EGF/RAS/RAF/MEK/ERK Signaling}

\section{Biology}

The RAS/RAF/MEK/ERK signaling pathway is involved in the regulation of different cellular processes, including cell proliferation, differentiation, survival and cell motility, and enables signal transduction from the cell surface to the cytoplasm and nucleus. Aberrant signaling drives tumor initiation and progression. Activated by cell surface receptors, small GTPase rat sarcoma oncogene homolog (RAS) binds to and consequently activates rapidly accelerated fibrosarcoma kinase (RAF). The clinically most relevant members of the RAS family are $\mathrm{H}-, \mathrm{K}-$, and N-RAS. RAF consists of 3 isoforms (A-, B-, C-RAF) with B-RAF as the major player in carcinogenesis. RAF phosphorylates MAPK and ERK kinase (MEK) which in turn activates the mitogen-activated protein kinases (MAPKs), including extracellular signal-regulated kinases (ERK) 1 and 2. ERK-1/-2 are the main effectors of this pathway with a variety of substrates (fig. 2 ).

Upregulation of the RAS/RAF/MEK/ERK pathway is commonly observed as a consequence of activating mutations in $B-R A F$ or RAS, with $K-R A S$ as the predominantly mutated $R A S$ gene in adenocarcinoma of the lung, pancreas, and colon [26, 27]. In addition, RAS can be activated by receptor tyrosine kinases, e.g. EGFR. Overexpression or mutational activation of EGFR is commonly found in cancer cells leading to upregulation of RAS/RAF/MEK/ ERK signaling and other pathways, including PI3K/Akt/mTOR signaling, signal transducer and activator of transcription (STAT) and protein kinase $\mathrm{C}$ (PKC), and phospholipase D pathways [28]. 


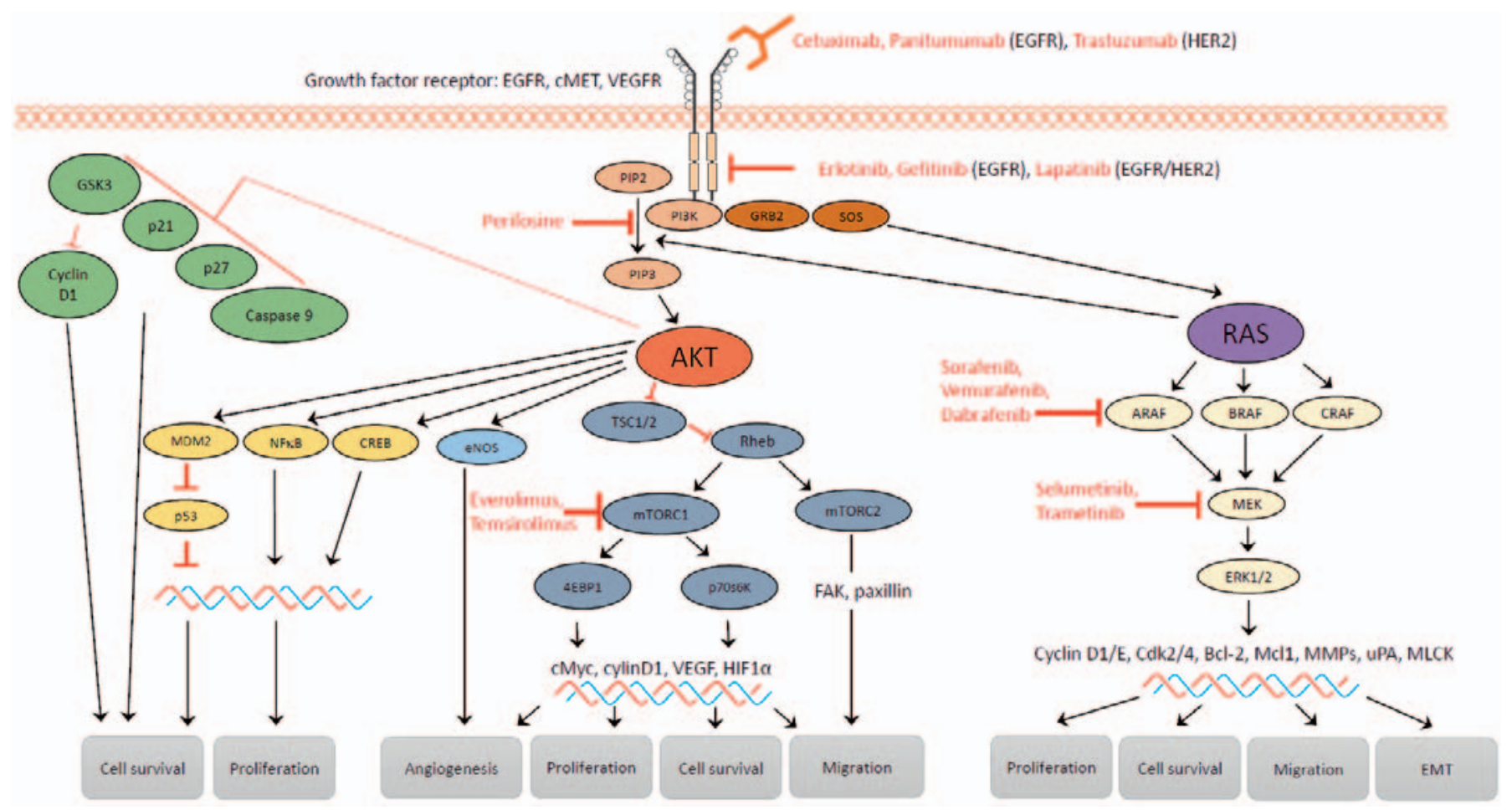

Fig. 2. EGFR signaling: key components of the RAS/RAF/MEK/ERK and PI3K/Akt/mTOR signaling pathways and their influence on the metastatic cascade. An activated receptor tyrosine kinase (e.g. EGFR) starts both cascades resulting in the activation of the downstream effectors Akt, mTORC-1/-2, and ERK. Available therapeutics targeting these signaling cascades are marked (cetuximab, panitumumab, trastuzumab, erlotinib, gefitinib, lapatinib, perifosine, sorafenib, vemurafenib, dabrafenib, selumetinib, trametinib, everolimus, temsirolimus).

\section{Influence on the Metastatic Cascade}

The RAS/RAF/MEK/ERK pathway is involved in the regulation of cell cycle progression. A-RAF has been shown to induce cells to enter the S-phase by upregulating the expression of cyclin-D1/-E and cyclin-dependent kinases (Cdk)-2/-4, and downregulating the expression of Cdk inhibitor p27 ${ }^{\mathrm{Kip} 1}$. B-RAF overexpression leads to cell cycle arrest and apoptosis [29]. Mediated by transcription factors AP-1, Ets-1 and NF- $\mathrm{KB}, \mathrm{RAS} / \mathrm{RAF} / \mathrm{MEK} / \mathrm{ERK}$ signaling induces expression of matrix-degrading proteases, MMP-1, -2, -3, -9 and $\mathrm{uPa}$ [30-33]. RAS (H-, K-, N-RAS) and its downstream effectors enhance tumor cell migration. ERK activates myosin lightchain kinase (MLCK) which increases cell movement and contraction by increasing phosphorylation of myosin light chain (MLC), the regulatory light chain of myosin II [34].

Inhibition of apoptosis is another consequence of RAS/RAF/ MEK/ERK signaling. Phosphorylating Bad allows Bcl-2 to generate an anti-apoptotic response. The anti-apoptotic Mcl-1 protein and the pro-apoptotic Bim protein are further apoptotic regulatory molecules which are phosphorylated as a result of RAS/RAF/MEK/ ERK signaling. Phosphorylating Bim results in its disassociation from Bcl-2/-X and Mcl-1, and degradation. RAF-1 was also shown to inhibit apoptosis independently from MEK and ERK, by regulating mammalian sterile 20-like kinase (MST-2) and ASK1 [29].

\section{Interventional Strategies}

One strategy to inhibit RAS/RAF/MEK/ERK signaling is to target the activating receptor EGFR. Various EGFR inhibitors have been successfully developed, including monoclonal antibodies against the extracellular domain (cetuximab, panitumumab) and small molecule tyrosine kinase inhibitors of the intracellular tyrosine kinase domain (erlotinib, gefitinib). Cetuximab and panitumumab are both approved for the treatment of metastatic colorectal cancer (CRC), cetuximab also for inoperable squamous cell cancer of the head and neck. Gefitinib and erlotinib are approved for the treatment of non-small cell lung cancer, erlotinib additionally for the first-line treatment of patients with locally advanced, unresectable, or metastatic pancreatic cancer. K-RAS mutations have shown to be associated with a lack of response to EGFR inhibition and to drive acquired resistance to cetuximab in CRCs $[35,36]$.

Another strategy to block RAS/RAF/MEK/ERK signaling is the inhibition of RAF. RAF inhibitors approved for anti-cancer treatment are the two B-RAF inhibitors, vemurafenib and dabrafenib, and sorafenib, which target RAF-1, B-RAF and mutant B-RAF V600E, and block receptor tyrosine kinase signaling (VEGF, platelet-derived growth factor receptor, c-Kit, and RET) [37-39].

MEK inhibitor trametinib, approved for treatment of metastatic melanoma with B-RAF V600E/K mutation, showed improved progression-free and overall survival for B-RAF V600 melanoma, but did not achieve a benefit in patients with untreated metastatic adenocarcinoma of the pancreas [38-40]. The MEK inhibitor selumetinib is approved for the treatment of stage III and IV differentiated thyroid cancer [41].

Reactivation of RAS/RAF/MEK/ERK signaling has been observed to drive resistance towards B-RAF and MEK inhibitors. 
Combining B-RAF and MEK inhibition could improve progression-free survival [39].

\section{PI3K/Akt/mTOR Signaling}

\section{Biology}

The PI3K/Akt/mTOR signaling pathway promotes cancer development as well as metastasis. Phosphatidylinositol-3-kinase (PI3K) can be activated by tyrosine kinases (e.g. EGFR) or by activated G protein-coupled receptors (e.g. RAS). Activated PI3K translocates to the plasma membrane and phosphorylates phosphatidylinositol 4,5-bisphosphate (PIP2), converting it into phosphatidylinositol 3,4,5-triphosphate (PIP3). Phosphatase and tensin homolog (PTEN) serves here as a negative regulator, converting PIP3 into PIP2. PIP3 activates serine/threonine kinase phosphoinositide-dependent kinase 1 (PDK1) and protein kinase-B (Akt). Subsequently, Akt phosphorylates tuberous sclerosis complex 2 (TSC2) which in its steady state forms a complex with TSC1. This complex converts active RAS homolog enriched in brain (RHEB) into its inactive form. As a result of PI3K activation, Akt inhibits the TSC1/-2 complex and enables RHEB to activate mammalian target of rapamycin (mTOR). mTOR functions as two structurally and functionally distinct multiprotein complexes: mTORC1/2 [42, 43] (fig. 2).

\section{Influence on the Metastatic Cascade}

$\mathrm{PI} 3 \mathrm{~K} / \mathrm{Akt} / \mathrm{mTOR}$ signaling triggers tumor cell motility and invasion. Both mTOR complexes promote tumor cell migration in different ways: mTORC1 induces migration and invasion of tumor cells via its downstream target p70 S6 kinase (S6K1) and eukaryotic initiation factor $4 \mathrm{E}$ binding protein (4E-BP1) [44]. Invasiveness is also achieved by upregulating matrix-remodeling enzymes such as MMP-2/-9, uPA, and plasminogen activator inhibitor-1 (PAI-1). mTORC2 regulates the actin cytoskeleton and cell motility by activating PKCa, GTPases, and focal adhesion proteins [45].

Besides migration and invasion, PI3K/Akt/mTOR signaling supports cell survival. Akt inactivates different pro-apoptotic factors like Bad and procaspase-9, and inhibits the expression of proapoptotic genes such as Fas ligand (FasL). Through its effectors S6K1 and 4E-BP1, mTOR controls cell cycle progression, cell growth, and cell size [46]. The PI3K/Akt/mTOR pathway plays an important role in angiogenesis. By increasing hypoxia inducible factor $1 \alpha($ HIF-1 $\alpha)$ translation, PI3K/Akt/mTOR signaling promotes VEGF expression [47].

\section{Interventional Strategies}

Several drugs targeting the PI3K/Akt/mTOR pathway are in clinical development. mTOR inhibitors temsirolimus and everolimus are approved for the treatment of advanced renal cell carcinoma. Everolimus is also FDA approved for the treatment of subependymal giant cell astrocytoma, advanced hormone receptor-positive and HER2-negative breast cancer, and progressive neuroendocrine tumors of pancreatic origin [48-50]. Perifosine, an alkyl-phospholipid, targets the PI3K/Akt/mTOR pathway by de-

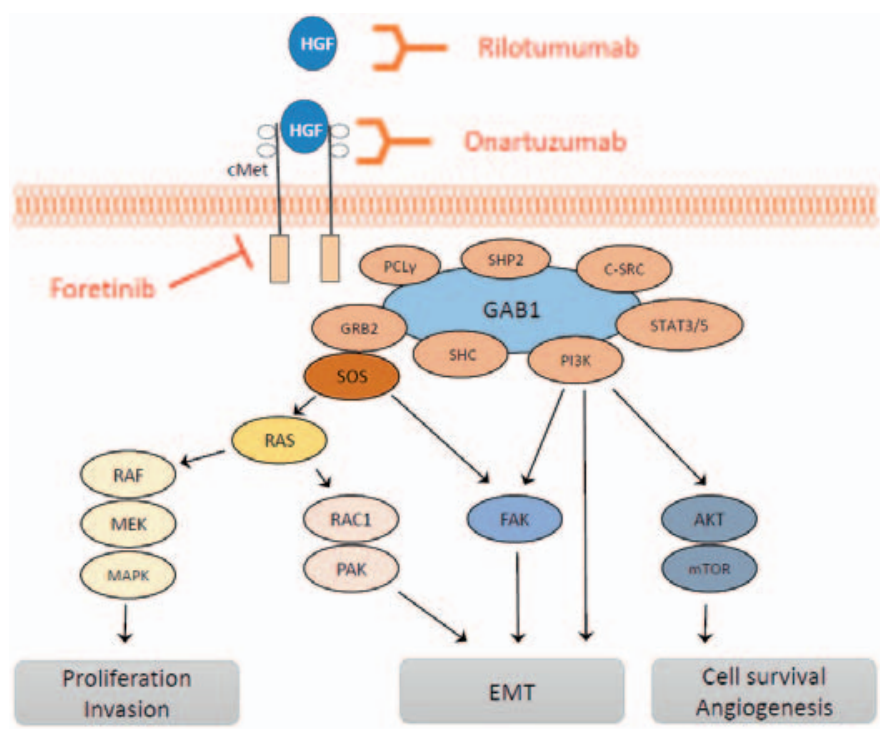

Fig. 3. cMet signaling and its influence on the metastatic cascade. HGF binds to the growth factor receptor cMet and activates downstream SHC, PI3K, STAT3/5, C-SRC, SHP2, PCL $\gamma$, GRB2, and SOS. This leads to the activation of RAS/RAF, RAS/RAC1m, FAK, and Akt/mTOR, and as a consequence to enhanced tumor proliferation, migration, invasion, EMT, cell survival, and angiogenesis. cMet is targetable by using the receptor antibodies rilotumumab or onartuzumab or the multikinase inhibitor foretinib.

creasing Akt phosphorylation. Given in combination with capecitabine, perifosine has shown to improve overall survival and time to progression in patients with metastatic CRC $[51,52]$.

\section{HGF/Met signaling}

\section{Biology}

Under normal physiological conditions, hepatocyte growth factor (HGF) binds to the cMet receptor tyrosine kinase and activates multiple signaling pathways mediating embryogenesis, tissue regeneration, and wound repair. In cancer, aberrant HGF/cMet signaling leads to increased cell migration, survival, and tumor progression [53].

After HGF binding to cMet, the tyrosine kinase is activated by autophosphorylation at different tyrosine residues. This leads to an activation of several downstream proteins like growth factor receptor-bound protein 2 (GRB2), Grb2-associated adaptor protein 1 (GAB1), PI3K, son of sevenless (SOS), RAS, MAPK, STAT-3/-5, SRC, SRC homology protein tyrosine phosphatase 2 (SHP2), SRC homology domain c-terminal adaptor homolog (SHC), phospholipase $c-\gamma$ (PLC), RAS-related C3 botulinum toxin substrate 1 (RAC1), p21-activated kinase (PAK), FAK, Akt, and mTOR (fig. 3).

\section{Influence on the Metastatic Cascade}

The activation of cMet and its downstream molecules has several effects on the cascade of metastasis. Local invasion is promoted by activation of PI3K/Akt/mTOR or FAK and affects EMT, invasion, and proliferation. Intravasation is promoted by increasing 


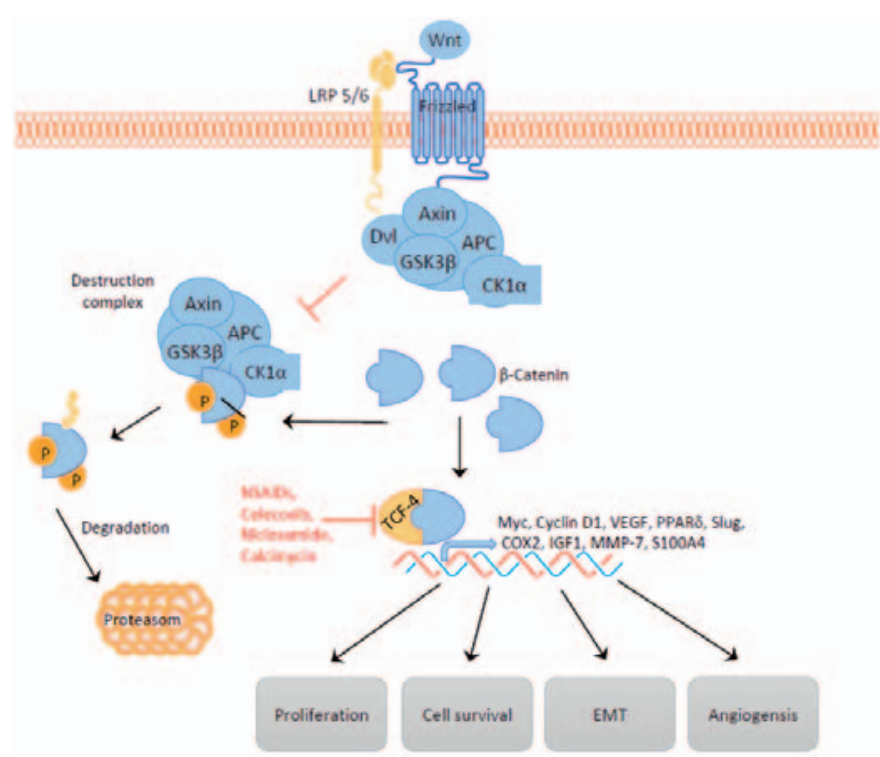

Fig. 4. Wnt signaling and its influence on the metastatic cascade. Wnt ligand binding leads to the inhibition of the destruction complex and consequently to the nucleic accumulation of $\beta$-catenin which drives Wnt gene expression. NSAIDs such as sulindac or celecoxib, the antibiotic calcimycin, and the anthelminthic niclosamide target $\beta$-catenin-dependent gene transcription.

neoangiogenesis. Involved pathways are STAT3, PI3K/Akt, and RAS. Additionally, cMet is a key regulator of the transcription factor HIF-1 $\alpha$. HIF-1a also promotes neoangiogenesis in hypoxic tissue [54].

\section{Interventional Strategies}

Different kinds of inhibitors of the HGF/cMet signaling pathway have been developed in the last years. Most advanced in clinical drug development are the monoclonal antibodies rilotumumab (against HGF) and onartuzumab (against the cMet receptor), and foretinib (multikinase inhibitor targeting cMet, RON, AXL, TIE-2 and VEGFR-2) [55-58]. From a biological perspective, alternate $\mathrm{HGF} / \mathrm{cMet}$ signaling is an important player in metastasis; however, for now, targeting cMet failed to show the expected effects in anticancer therapy $[56,59]$. Stratifying patients for cMet-targeted therapy may improve outcome.

\section{Metastasis Enhancer: MACC1}

Recently, metastasis-associated in colon cancer 1 (MACC1) was identified with differential display reverse transcription polymerase chain reaction by analyzing normal mucosa and primary/metastasis specimens of colon cancer. Prognostic relevance was shown for both patient survival and development of metastases. Stein et al. [60] showed a high 5-year survival rate of $80 \%$ for CRC patients with low MACC1 expression, while for patients with high MACC1 expression the 5 -year survival rate was only $15 \%$. This finding was validated by many groups for CRC and a broad variety of solid tumor types when analyzing patient tissue or blood [61-64].

\section{Biology and Influence on the Metastatic Cascade}

MACC1 functions as a main regulator of the HGF/cMet signaling axis. $\mathrm{HGF} / \mathrm{cMet}$ signaling induces MACC1 expression via RAS/ MAPK signaling. MACC1 protein in turn activates cMet expression resulting in a positive feedback loop. MACC1 exerts its metastatic potential via interacting with different pathways, such as cMet, Akt, and $\beta$-catenin.

For various cancer cell lines, MACC1 has proven to induce proliferation and inhibit apoptosis $[65,66]$. Furthermore, several studies have revealed MACC1 to induce EMT by increasing the mesenchymal phenotype markers vimentin and CD44 and suppressing the epithelial phenotype markers E-cadherin and $\alpha$-catenin [6668]. Recently, Wang et al. [69] showed that MACC1 upregulates Twist-1/-2, a key EMT switch transcriptional regulator. MACC1 also regulates the pluripotency markers Oct4 and Nanog. Overexpression of Oct 4 and Nanog contributes to the stem cell phenotype of tumor cells [70]. MACC1 is also involved in migration, invasion, and angiogenesis [65-67, 71-73]. Additionally, overexpression of MACC1 facilitates tumor blood supply by inducing vasculogenic mimicry, the formation of vascular channels in the absence of endothelial cells and fibroblasts [69]. As MACC1 plays an important role in multiple aspects of carcinogenesis and metastasis, it seems to be a promising interventional target.

\section{Wnt/ $\beta$-Catenin Signaling}

Biology

During embryonic development, Wnt signaling plays a fundamental role in the regulation of cell proliferation, polarity, and determination of cell fate. In the absence of Wnt signaling, intracellular $\beta$-catenin levels are regulated by way of a multiprotein complex. This complex consists of the scaffolding protein Axin, the tumor suppressor adenomatous polyposis coli protein (APC), glycogen synthase kinase-3 $\beta$ (GSK3 $\beta$ ), and casein kinase 1 (CK1). By binding and phosphorylating, the destruction complex targets cytoplasmic $\beta$-catenin for ubiquitination and proteasomal degradation. As a consequence of continuous elimination, $\beta$-catenin does not reach the nucleus. The DNA-bound T-cell factor/lymphoid enhancer factor (TCF/LEF) family of transcription factors are the main partner for $\beta$-catenin in the regulation of gene expression. In the absence of nuclear $\beta$-catenin, TCF/LEF represses gene expression by binding to the transcriptional co-repressors Groucho/TLE.

Wnt ligands binding to the Frizzled receptor and its co-receptor low-density lipoprotein receptor-related proteins (LRP) activates the Wnt/ $\beta$-catenin pathway. Activation leads to the inhibition of the destruction complex and consequently to stabilization, accumulation, and nucleic translocation of $\beta$-catenin. In the nucleus, $\beta$-catenin activates Wnt target gene expression by binding to TCF/ LEF and displacing the transcriptional co-repressors Groucho/TLE [74, 75] (fig. 4).

A large number of sporadic CRC show inactivating mutations in the APC gene [76]. Additionally, APC germline mutations cause familial adenomatous polyposis (FAP). Loss of APC function leads 
to inappropriate stabilization of $\beta$-catenin and thus enhanced Wnt target gene expression.

\section{Influence on the Metastatic Cascade}

$\mathrm{Wnt} / \beta$-catenin signaling induces EMT via upregulating Axin2, member of the destruction complex and downstream target of Wnt signaling. Upregulated Axin2 leads to stabilization of the transcription factor Snail. Active Snail represses E-cadherin expression [75]. Furthermore, $\beta$-catenin-mediated transcription induces expression of Slug and thereby inhibits E-cadherin transcription. E-cadherin loss in the tumor results in release of its binding partner $\beta$-catenin and consequently in the transcriptional reduction of E-cadherin [77]. Loss of E-cadherin induces transcription factors such as Twist and ZEB1, and enables metastasis by inducing EMT, invasiveness, and anoikis resistance [78]. ZEB1 is indirectly activated by Wnt signaling via the Wnt target genes cyclooxygenase-2 (COX-2) and IGF1 [79].

Proliferation and migration of cancer cells as well as of endothelial cells are promoted by Wnt signaling. Both in cancer cells and in vascular smooth muscle cells, cyclin-D1 and c-myc, proliferation-associated proteins, are upregulated in response to Wnt signaling. Cyclin-D1 is involved in cell cycle progression through G1. COX-2 has been shown to be upregulated by nuclear $\beta$-catenin accumulation. Together with its metabolite prostaglandin E2 (PGE2), it has been shown to exert important effects in cancer cells, promoting proliferation, survival, migration, invasion, and angiogenesis $[80,81]$.

\section{Interventional Strategies}

As COX-2 is involved in Wnt signaling and contributes to tumorigenesis, COX-2 inhibition seems to be a promising therapeutic strategy. PGE2 leads to the stabilization and nuclear translocation of $\beta$-catenin via PI3K/Akt signaling. COX enzyme inhibition decreases the synthesis of PGE2 and as a consequence the activation of $\beta$-catenin signaling $[82,83]$. Non-steroidal anti-inflammatory drugs (NSAIDs) have been shown to induce apoptosis and inhibit proliferation via COX-2-dependent und -independent mechanisms in CRC cells $[84,85]$. For patients with FAP, celecoxib is approved for the reduction of colorectal polyps [86]. Nevertheless, adding celecoxib to irinotecan/fluoropyrimidine regimens failed to produce any survival benefit for metastatic CRC patients [87].

\section{Wnt Signaling Target: S100A4}

\section{Biology}

S100A4 is a member of the S100 family of calcium-binding proteins. Enhanced expression of S100A4 has been reported for different cancer types in both tumor tissues and blood. For cancer patients, high mRNA and protein levels of S100A4 have shown to correlate with decreased overall and disease-free survival. Overexpression is correlated with aggressive tumor growth and formation of metastasis [88-91].

S100A4 is a transcriptional target of $\beta$-catenin [88]. It is located in the cytoplasm, the nucleus, and the extracellular space. Extracel- lular S100A4 shows interaction with the receptor of advanced glycation end products (RAGE), annexin II, and heparin sulfate proteoglycans [92].

\section{Influence on the Metastatic Cascade}

S100A4 promotes metastasis by inducing SAA-1/-3 expression via Toll-like receptor 4 (TLR4)/NF- $\kappa B$ signaling. SAA proteins induce the expression of RANTES, G-CSF, and MMP-2, -3, -9 and -13. Ectopic SAA expression was shown to support formation of metastases and was accompanied by a massive infiltration of immune cells [89].

Tumor cell motility and invasion are promoted by $\mathrm{S} 100 \mathrm{~A} 4$ expression. The interaction of S100A4 and RAGE was shown to increase RAS/RAF/MEK/ERK signaling and HIF-1a protein levels. As a result, cells showed enhanced migration and invasion. By directly interacting with myosin IIA at the leading edge of migrating cells, S100A4 enhances tumor cell motility $[92,93]$.

Furthermore, S100A4 expression has been identified to correlate with angiogenesis and higher vessel density in neoplastic lesions $[94,95]$. Several studies showed S100A4 to be protective against pro-apoptotic stimuli [96-98]. Orre et al. [99] showed that S100A4 interacts with the tumor suppressor p53 in the nucleus and promotes p53 degradation. Knockdown of S100A4 leads to a p53-dependent growth arrest and increases cisplatin-induced apoptosis.

Supporting the formation of metastasis in many different ways, S100A4 is a promising therapeutic target for cancer treatment.

\section{VEGF Signaling}

\section{Biology}

VEGF, an endothelial cell mitogen, is capable of inducing physiological as well as pathological angiogenesis. The VEGF family includes VEGF-A, -B, -C, -D, and PlGF. VEGF signaling is mediated by three VEGF receptor tyrosine kinases and neuropilins (NRPs): VEGFR-1, -2, and -3. VEGF binding leads to receptor autophosphorylation, resulting in the activation of signaling pathways. Besides endothelial cells, tumor cells express VEGF receptors and respond to both autocrine and paracrine VEGF signaling. Hypoxia is a major stimulus for increased VEGF production in tumor cells. Both STAT3 and HIF-1 $\alpha$ bind to the VEGF promoter and induce transcription of VEGF in response to hypoxia $[47,100]$. NRPs are transmembrane glycoproteins and have been shown to function as a co-receptor for VEGF. By forming complexes with VEGFRs, NRPs can affect the activity of VEGFR-1/-2 [100, 101].

\section{Influence on the Metastatic Cascade}

The VEGF pathway is a central regulator of angiogenesis in the process of metastatic spread. VEGFR-2 is the predominant receptor mediating VEGF signaling in endothelial cells and thus VEGFmediated angiogenesis. VEGFR-2/VEGF-A signaling in endothelial cells induces proliferation via MAPK signaling and migration via FAK/paxillin, p38/MAPK, and PI3K signaling. VEGF-mediated PI3K/Akt signaling also sustains survival of endothelial cells and 
expression of eNOS. FAK/paxillin enhances vascular permeability [12, 47, 102-104].

In tumor cells, VEGFR-1 signaling promotes growth, migration, and invasion of tumor cells by stimulating the activation of ERK$1 /-2$ as well as c-Jun $\mathrm{NH}_{2}$-terminal kinase (JNK). A link between VEGF signaling and tumor dedifferentiation has been suggested. Autocrine VEGF expression is characteristic for poorly differentiated carcinomas and can promote growth, survival, migration, and invasion of cancer cells. Additionally, EMT was shown to be induced in normal epithelial cells and differentiated carcinoma cells via VEGF [105].

VEGF-C/-D, which act through VEGFR-3, are central regulators of lymphangiogenesis in cancer. Elevated VEGF-C/-D expression is strongly associated with enhanced lymphatic vessel density and increased rates of lymph node metastasis [106-108]. VEGFR-3 activation in lymphatic endothelial cells induces cell proliferation and migration and protection from apoptosis. Involved pathways include $\mathrm{p} 42 / \mathrm{p} 44, \mathrm{MAPK}$, and Akt signaling [108].

\section{Interventional Strategies}

Several strategies to inhibit VEGF signaling for cancer treatment have been explored. Anti-angiogenic VEGF inhibitors approved by the FDA for cancer treatment are antibodies against VEGF (bevacizumab) and VEGFR-2 (ramucirumab), recombinant fusion protein against VEGF-A (aflibercept), and tyrosine kinase inhibitors (axitinib, regorafenib, sorafenib, sunitinib, cabozantinib, vandetanib, pazopanib). However, in a considerable fraction of patients, VEGFtargeted therapy failed to show clinical benefit $[100,109]$.

\section{Conclusion}

Metastatic spread of cancer cells is a complex process with countless different genes and pathways involved. Cancer cells have to undergo a multistep process to reach metastatic potential, finally forming metastasis at distant organs. Here, we provided an overview of the most important pathways and genes involved in the formation of metastasis. However, there are various other regulators of the metastatic cascade which have to be addressed as well: The immune system plays an important role in nearly every step of the metastatic cascades with monocytes, macrophages, neutrophils,
T-lymphocytes, and natural killer cells as key players. Targeting immune pathways is a very promising strategy for the treatment of metastatic cancer and has shown success in preclinical models. Immune checkpoint blockade therapy is already approved for patients with metastatic disease. The anti-CTLA-4 monoclonal antibody ipilimumab has shown significantly improved overall survival for advanced unresectable melanoma [110, 111]. Furthermore, microRNAs have been reported to play a role in tumorigenesis and the formation of metastasis. microRNAs have a function in RNA silencing and post-transcriptional regulation of gene expression. Altered microRNA expression is reported for various cancer types and is involved in different steps of the metastatic cascade. Some microRNAs (e.g. miR-10b, miR-9) have been reported to promote metastasis by inducing EMT, proliferation, invasion, and migration. Other microRNAs suppress the formation of metastasis (e.g. miR-34a, miR-206, miR-335, miR-126) via inhibiting cancer stem cell properties, inducing apoptosis, and inhibiting migration and EMT. First specific microRNA mimics and inhibitors are being tested in clinical trials for the treatment of cancer or infectious diseases [112]. Additionally, there is growing interest in the mechanism of metastatic latency, long non-coding RNAs, exosomes, and cancer stem cells as further crucial promoters of metastasis and potential therapeutic targets.

In summary, metastasis is a multifactorial process with many promoting and inhibiting factors. Analyzing every step is a necessary approach to develop interventional anti-cancer therapies and improve patient survival.

\section{Acknowledgment}

E.P. was supported by a grant from the Berlin Society of Cancer ('Berliner Krebsgesellschaft')

C.T. is participant in the Charite Clinical Scientist Program funded by the Charité - University Medicine Berlin and the Berlin Institute of Health.

\section{Disclosure Statement}

Eva Pachmayr, Christoph Treese and Ulrike Stein have no conflicts of interest or financial ties to disclose.

\section{References}

1 Paget S: The distribution of secondary growths in cancer of the breast. 1889. Cancer Metastasis Rev 1989;8: 98-101.

2 Talmadge JE, Fidler IJ: AACR centennial series: the biology of cancer metastasis: historical perspective. Cancer Res 2010;70:5649-5669.

3 Meacham CE, Morrison SJ: Tumour heterogeneity and cancer cell plasticity. Nature 2013;501:328-337.

4 Klein CA: Parallel progression of primary tumours and metastases. Nat Rev Cancer 2009;9:302-312.
5 Fidler IJ: The pathogenesis of cancer metastasis: the 'seed and soil' hypothesis revisited. Nat Rev Cancer 2003;3:453-458.

6 Valastyan S, Weinberg RA: Tumor metastasis: molecular insights and evolving paradigms. Cell 2011;147: 275-292.

7 Guan X: Cancer metastases: challenges and opportunities. Acta Pharm Sin B 2015;5:402-418.

8 Thiery JP, Acloque H, Huang RY, Nieto MA: Epithelial-mesenchymal transitions in development and disease. Cell 2009;139:871-890.
9 Lauffenburger DA, Horwitz AF: Cell migration: a physically integrated molecular process. Cell 1996;84: 359-369.

10 Chiang SP, Cabrera RM, Segall JE: Tumor cell intravasation. Am J Physiol Cell Physiol 2016;311:C1-C14.

11 Balkwill FR, Capasso M, Hagemann T: The tumor microenvironment at a glance. J Cell Sci 2012;125:55915596.

12 Zingg U, Montani M, Frey DM, Dirnhofer S, Esterman AJ, Went P, Oertli D: Tumour-infiltrating lymphocytes and survival in patients with adenocarcinoma of the oesophagus. Eur J Surg Oncol 2010;36:670-677. 
13 Berlth F, Bollschweiler E, Drebber U, Hoelscher AH, Moenig S: Pathohistological classification systems in gastric cancer: diagnostic relevance and prognostic value. World J Gastroenterol 2014;20:5679-5684.

14 Hanahan D, Weinberg RA: Hallmarks of cancer: the next generation. Cell 2011;144:646-674.

15 Fidler IJ: Metastasis: quantitative analysis of distribution and fate of tumor emboli labeled with 125 i-5iodo-2'-deoxyuridine. J Natl Cancer Inst 1970;45:773782.

16 Pantel K, Speicher MR: The biology of circulating tumor cells. Oncogene 2016;35:1216-1224.

17 Joyce JA, Pollard JW: Microenvironmental regulation of metastasis. Nat Rev Cancer 2009;9:239-252.

18 Yan M, Jurasz P: The role of platelets in the tumor microenvironment: from solid tumors to leukemia. Biochim Biophys Acta 2016;1863:392-400.

19 Sarvaiya PJ, Guo D, Ulasov I, Gabikian P, Lesniak MS: Chemokines in tumor progression and metastasis. Oncotarget 2013;4:2171-2185.

20 Kaplan RN, Riba RD, Zacharoulis S, et al: VEGFR1positive haematopoietic bone marrow progenitors initiate the pre-metastatic niche. Nature 2005;438:820827.

21 Lukanidin E, Sleeman JP: Building the niche: the role of the $\mathrm{S} 100$ proteins in metastatic growth. Semin Cancer Biol 2012;22:216-225.

22 Chin AR, Wang SE: Cancer tills the premetastatic field mechanistic basis and clinical implications. Clin Cancer Res 2016;22:3725-3733.

23 Psaila B, Lyden D: The metastatic niche: adapting the foreign soil. Nat Rev Cancer 2009;9:285-293.

24 Braun S, Vogl FD, Naume B, et al: A pooled analysis of bone marrow micrometastasis in breast cancer. $\mathrm{N}$ Engl J Med 2005;353:793-802.

25 Malladi S, Macalinao DG, Jin X, He L, Basnet H, Zou Y, de Stanchina E, Massague J: Metastatic latency and immune evasion through autocrine inhibition of WNT. Cell 2016;165:45-60.

26 Campbell PM, Der CJ: Oncogenic Ras and its role in tumor cell invasion and metastasis. Semin Cancer Biol 2004;14:105-114.

27 Bos JL: Ras oncogenes in human cancer: a review. Cancer Res 1989;49:4682-4689.

28 Roberts PJ, Der CJ: Targeting the Raf-MEK-ERK mitogen-activated protein kinase cascade for the treatment of cancer. Oncogene 2007;26:3291-3310.

29 McCubrey JA, Steelman LS, Chappell WH, Abrams SL Wong EW, Chang F, Lehmann B, Terrian DM, Milella M, Tafuri A, Stivala F, Libra M, Basecke J, Evangelisti C, Martelli AM, Franklin RA: Roles of the Raf/MEK/ERK pathway in cell growth, malignant transformation and drug resistance. Biochim Biophys Acta 2007;1773:12631284

30 Westermarck J, Li SP, Kallunki T, Han J, Kahari VM: P38 mitogen-activated protein kinase-dependent activation of protein phosphatases 1 and $2 \mathrm{~A}$ inhibits MEK1 and MEK2 activity and collagenase 1 (MMP-1) gene expression. Mol Cell Biol 2001;21:2373-2383.

31 Tang CH, Tsai CC: CCL2 increases MMP-9 expression and cell motility in human chondrosarcoma cells via the Ras/Raf/MEK/ERK/NF-kB signaling pathway. Biochem Pharmacol 2012;83:335-344.

32 Ozanne BW, Spence HJ, McGarry LC, Hennigan RF: Transcription factors control invasion: AP-1 the first among equals. Oncogene 2007;26:1-10.

33 Irigoyen JP, Besser D, Nagamine Y: Cytoskeleton reorganization induces the urokinase-type plasminogen activator gene via the Ras/extracellular signal-regulated kinase (ERK) signaling pathway. J Biol Chem 1997;272:1904-1909.

34 Klemke RL, Cai S, Giannini AL, Gallagher PJ, de Lanerolle P, Cheresh DA: Regulation of cell motility by mitogen-activated protein kinase. J Cell Biol 1997;137: 481-492.
35 Normanno N, Tejpar S, Morgillo F, De Luca A, Van Cutsem E, Ciardiello F: Implications for KRAS status and EGFR-targeted therapies in metastatic CRC. Nat Rev Clin Oncol 2009;6:519-527.

36 Misale S, Yaeger R, Hobor S, et al: Emergence of KRAS mutations and acquired resistance to anti-EGFR therapy in colorectal cancer. Nature 2012;486:532-536.

37 Wilhelm S, Carter C, Lynch M, Lowinger T, Dumas J, Smith RA, Schwartz B, Simantov R, Kelley S: Discovery and development of sorafenib: a multikinase inhibitor for treating cancer. Nat Rev Drug Discov 2006;5:835844

38 Tran KA, Cheng MY, Mitra A, Ogawa H, Shi VY, Olney LP, Kloxin AM, Maverakis E: MEK inhibitors and their potential in the treatment of advanced melanoma: the advantages of combination therapy. Drug Des Devel Ther 2016;10:43-52.

39 Flaherty KT, Infante JR, Daud A, et al: Combined BRAF and MEK inhibition in melanoma with BRAF V600 mutations. N Engl J Med 2012;367:1694-1703.

40 Infante JR, Somer BG, Park JO, Li CP, Scheulen ME, Kasubhai SM, Oh DY, Liu Y, Redhu S, Steplewski K, Le $\mathrm{N}$ : A randomised, double-blind, placebo-controlled trial of trametinib, an oral MEK inhibitor, in combination with gemcitabine for patients with untreated metastatic adenocarcinoma of the pancreas. Eur J Cancer 2014;50:2072-2081.

41 Ho AL, Grewal RK, Leboeuf R, Sherman EJ, Pfister DG, Deandreis D, Pentlow KS, Zanzonico PB, Haque S, Gavane S, Ghossein RA, Ricarte-Filho JC, Dominguez JM, Shen R, Tuttle RM, Larson SM, Fagin JA: Selumetinibenhanced radioiodine uptake in advanced thyroid cancer. N Engl J Med 2013;368:623-632.

42 Polivka J Jr, Janku F: Molecular targets for cancer therapy in the PI3K/AKT/mTOR pathway. Pharmacol Ther 2014;142:164-175.

43 Agarwal E, Brattain MG, Chowdhury S: Cell survival and metastasis regulation by AKT signaling in colorectal cancer. Cell Signal 2013;25:1711-1719.

44 Liu L, Li F, Cardelli JA, Martin KA, Blenis J, Huang S: Rapamycin inhibits cell motility by suppression of mTOR-mediated S6K1 and 4E-BP1 pathways. Oncogene 2006;25:7029-7040

45 Zhou H, Huang S: Role of mTOR signaling in tumor cell motility, invasion and metastasis. Curr Protein Pept Sci 2011;12:30-42.

46 Fingar DC, Richardson CJ, Tee AR, Cheatham L, Tsou C, Blenis J: mTOR controls cell cycle progression through its cell growth effectors S6K1 and 4E-BP1/eukaryotic translation initiation factor $4 \mathrm{E}$. Mol Cell Biol 2004;24:200-216

47 Karar J, Maity A: PI3K/AKT/mTOR pathway in angiogenesis. Front Mol Neurosci 2011;4:51

48 Hudes G, Carducci M, Tomczak P, Dutcher J, Figlin R, Kapoor A, Staroslawska E, Sosman J, McDermott D, Bodrogi I, Kovacevic Z, Lesovoy V, Schmidt-Wolf IGH, Barbarash O, Gokmen E, O’Toole T, Lustgarten S, Moore L, Motzer RJ: Temsirolimus, interferon alfa, or both for advanced renal-cell carcinoma. N Engl J Med 2007;356:2271-2281.

49 Baselga J, Campone M, Piccart M, et al: Everolimus in postmenopausal hormone-receptor-positive advanced breast cancer. N Engl J Med 2012;366:520-529.

50 Yao JC, Shah MH, Ito T, Bohas CL, Wolin EM, Van Cutsem E, Hobday TJ, Okusaka T, Capdevila J, de Vries EG, Tomassetti P, Pavel ME, Hoosen S, Haas T, Lincy J, Lebwohl D, Oberg K: Everolimus for advanced pancreatic neuroendocrine tumors. N Engl J Med 2011; 364:514-523.

51 Richardson PG, Eng C, Kolesar J, Hideshima T, Anderson KC: Perifosine, an oral, anti-cancer agent and inhibitor of the AKT pathway: mechanistic actions, pharmacodynamics, pharmacokinetics, and clinical activity. Expert Opin Drug Metab Toxicol 2012;8:623633.
52 Bendell JC, Nemunaitis J, Vukelja SJ, Hagenstad C, Campos LT, Hermann RC, Sportelli P, Gardner L, Richards DA: Randomized placebo-controlled phase II trial of perifosine plus capecitabine as second- or third-line therapy in patients with metastatic colorectal cancer. J Clin Oncol 2011;29:4394-4400.

53 Zhang Y, Du Z, Zhang M: Biomarker development in MET-targeted therapy. Oncotarget 2016;7:3737037389

54 Samame Perez-Vargas JC, Biondani P, Maggi C, Gariboldi M, Gloghini A, Inno A, Volpi CC, Gualeni AV, di Bartolomeo M, de Braud F, Castano A, Bossi I, Pietrantonio F: Role of cMET in the development and progression of colorectal cancer. Int J Mol Sci 2013;14 18056-18077.

55 Iveson T, Donehower RC, Davidenko I, Tjulandin S, Deptala A, Harrison M, Nirni S, Lakshmaiah K, Thomas A, Jiang Y, Zhu M, Tang R, Anderson A, Dubey S, Oliner KS, Loh E: Rilotumumab in combination with epirubicin, cisplatin, and capecitabine as first-line treatment for gastric or oesophagogastric junction adenocarcinoma: an open-label, dose de-escalation phase $1 \mathrm{~b}$ study and a double-blind, randomised phase 2 study. Lancet Oncol 2014;15:1007-1018.

56 Cunningham D, Tebbutt NC, Davidenko I, Murad AM, Al-Batran S-E, Ilson DH, Tjulandin S, Gotovkin E, Karaszewska B, Bondarenko I: Phase III, randomized, double-blind, multicenter, placebo $(\mathrm{P})$-controlled trial of rilotumumab (R) plus epirubicin, cisplatin and capecitabine (ECX) as first-line therapy in patients (pts) with advanced met-positive (pos) gastric or gastroesophageal junction (G/GEJ) cancer: RILOMET-1 study. ASCO Ann Meet Proc 2015;33:abstr 4000.

57 Shah MA, Bang Y-J, Lordick F, Tabernero J, Chen M Hack SP, Phan S-C, Shames DS, Cunningham D: METGastric: a phase III study of onartuzumab plus mFOLFOX6 in patients with metastatic HER2-negative (HER2-) and MET-positive (MET+) adenocarcinoma of the stomach or gastroesophageal junction (GEC): ASCO Ann Meet Proc 2015;33:abstr 4012.

58 Shah MA, Wainberg ZA, Catenacci DV, Hochster HS, Ford J, Kunz P, Lee FC, Kallender H, Cecchi F, Rabe DC, Keer H, Martin AM, Liu Y, Gagnon R, Bonate P, Liu L, Gilmer T, Bottaro DP: Phase II study evaluating 2 dosing schedules of oral foretinib (GSK1363089), cMET/VEGFR2 inhibitor, in patients with metastatic gastric cancer. PLoS One 2013;8:e54014.

59 Shah MA, Cho JY, Tan IB, Tebbutt NC, Yen CJ, Kang A, Shames DS, Bu L, Kang YK: A randomized phase II study of FOLFOX with or without the MET inhibitor onartuzumab in advanced adenocarcinoma of the stomach and gastroesophageal junction. Oncologist 2016;21:1085-1090.

60 Stein U, Walther W, Arlt F, Schwabe H, Smith J, Fichtner I, Birchmeier W, Schlag PM: MACC1, a newly identified key regulator of HGF-MET signaling, predicts colon cancer metastasis. Nat Med 2009;15: 59-67.

61 Wang G, Fu Z, Li D: MACC1 overexpression and survival in solid tumors: a meta-analysis. Tumour Biol 2015;36:1055-1065.

62 Wu Z, Zhou R, Su Y, Sun L, Liao Y, Liao W: Prognostic value of MACC1 in digestive system neoplasms: a systematic review and meta-analysis. Biomed Res Int 2015;2015:252043.

63 Burock S, Herrmann P, Wendler I, Niederstrasser M Wernecke KD, Stein U: Circulating Metastasis Associated in Colon Cancer 1 transcripts in gastric cancer patient plasma as diagnostic and prognostic biomarker. World J Gastroenterol 2015;21:333-341.

64 Wang Z, Cai M, Weng Y, Zhang F, Meng D, Song J, Zhou H, Xie Z: Circulating MACC1 as a novel diagnostic and prognostic biomarker for nonsmall cell lung cancer. J Cancer Res Clin Oncol 2015;141:1353-1361. 
65 Meng F, Li H, Shi H, Yang Q, Zhang F, Yang Y, Kang L, Zhen T, Dai S, Dong Y, Han A: MACC1 down-regulation inhibits proliferation and tumourigenicity of nasopharyngeal carcinoma cells through $\mathrm{Akt} / \beta$-catenin signaling pathway. PLoS One 2013;8:e60821.

66 Zhen T, Dai S, Li H, Yang Y, Kang L, Shi H, Zhang F, Yang D, Cai S, He Y, Liang Y, Han A: MACC1 promotes carcinogenesis of colorectal cancer via $\beta$-catenin signaling pathway. Oncotarget 2014;5:3756-3769.

67 Wang L, Wu Y, Lin L, Liu P, Huang H, Liao W, Zheng D, Zuo Q, Sun L, Huang N, Shi M, Liao Y, Liao W: Metastasis-associated in colon cancer-1 upregulation predicts a poor prognosis of gastric cancer, and promotes tumor cell proliferation and invasion. Int J Cancer 2013;133:1419-1430.

68 Wang G, Kang MX, Lu WJ, Chen Y, Zhang B, Wu YL: MACC1: a potential molecule associated with pancreatic cancer metastasis and chemoresistance. Oncol Lett 2012;4:783-791.

69 Wang L, Lin L, Chen X, Sun L, Liao Y, Huang N, Liao $\mathrm{W}$ : Metastasis-associated in colon cancer-1 promotes vasculogenic mimicry in gastric cancer by upregulating TWIST1/2. Oncotarget 2015;6:11492-11506.

70 Lemos C, Hardt MS, Juneja M, Voss C, Forster S, Jerchow B, Haider W, Blaker H, Stein U: MACC1 induces tumor progression in transgenic mice and colorectal cancer patients via increased pluripotency markers Nanog and Oct4. Clin Cancer Res 2016;22:2812-2824.

71 Schmid F, Wang Q, Huska MR, Andrade-Navarro MA, Lemm M, Fichtner I, Walther W, Schlag PM, Stein US: S100p, a target gene of MACC1, contributes to colorectal cancer metastasis. Cancer Res 2013;73: abstr 416 .

72 Schmid F, Wang Q, Huska MR, Andrade-Navarro MA, Lemm M, Fichtner I, Dahlmann M, Kobelt D, Walther W, Smith J, Schlag PM, Stein U: SPON2, a newly identified target gene of MACC1, drives colorectal cancer metastasis in mice and is prognostic for colorectal cancer patient survival. Oncogene 2016;35: 5942-5952.

73 Sun L, Duan J, Jiang Y, Wang L, Huang N, Lin L, Liao $\mathrm{Y}$, Liao W: Metastasis-associated in colon cancer-1 upregulates vascular endothelial growth factor-C/D to promote lymphangiogenesis in human gastric cancer. Cancer Lett 2015;357:242-253.

74 Daniels DL, Weis WI: Beta-catenin directly displaces Groucho/TLE repressors from Tcf/Lef in Wnt-mediated transcription activation. Nat Struct Mol Biol 2005; 12:364-371

75 Fodde R, Brabletz T: Wnt/beta-catenin signaling in cancer stemness and malignant behavior. Curr Opin Cell Biol 2007;19:150-158

76 Luchtenborg M, Weijenberg MP, Roemen GM, de Bruine AP, van den Brandt PA, Lentjes MH, Brink M, van Engeland M, Goldbohm RA, de Goeij AF: APC mutations in sporadic colorectal carcinomas from The Netherlands Cohort Study. Carcinogenesis 2004;25: 1219-1226.

77 Conacci-Sorrell M, Simcha I, Ben-Yedidia T, Blechman J, Savagner P, Ben-Ze'ev A: Autoregulation of Ecadherin expression by cadherin-cadherin interactions: the roles of beta-catenin signaling, Slug, and MAPK. J Cell Biol 2003;163:847-857.

78 Onder TT, Gupta PB, Mani SA, Yang J, Lander ES Weinberg RA: Loss of E-cadherin promotes metastasis via multiple downstream transcriptional pathways. Cancer Res 2008;68:3645-3654.

79 Schmalhofer O, Brabletz S, Brabletz T: E-cadherin, beta-catenin, and ZEB1 in malignant progression of cancer. Cancer Metastasis Rev 2009;28:151-166.

80 Gately S, Li WW: Multiple roles of COX-2 in tumor angiogenesis: a target for antiangiogenic therapy. Semin Oncol 2004;31:2-11.
81 Greenhough A, Smartt HJ, Moore AE, Roberts HR, Williams AC, Paraskeva C, Kaidi A: The COX-2/PGE2 pathway: key roles in the hallmarks of cancer and adaptation to the tumour microenvironment. Carcinogenesis 2009;30:377-386.

82 Castellone MD, Teramoto H, Williams BO, Druey KM, Gutkind JS: Prostaglandin E2 promotes colon cancer cell growth through a Gs-axin-beta-catenin signaling axis. Science 2005;310:1504-1510.

83 Boon EM, Keller JJ, Wormhoudt TA, Giardiello FM, Offerhaus GJ, van der Neut R, Pals ST: Sulindac targets nuclear beta-catenin accumulation and Wnt signalling in adenomas of patients with familial adenomatous polyposis and in human colorectal cancer cell lines. $\mathrm{Br}$ J Cancer 2004;90:224-229.

84 Maier TJ, Schilling K, Schmidt R, Geisslinger G, Grosch S: Cyclooxygenase-2 (COX-2)-dependent and -independent anticarcinogenic effects of celecoxib in human colon carcinoma cells. Biochem Pharmacol 2004;67:1469-1478.

85 Smith ML, Hawcroft G, Hull MA: The effect of nonsteroidal anti-inflammatory drugs on human colorectal cancer cells: evidence of different mechanisms of action. Eur J Cancer 2000;36:664-674.

86 Steinbach G, Lynch PM, Phillips RK, et al: The effect of celecoxib, a cyclooxygenase- 2 inhibitor, in familial adenomatous polyposis. N Engl J Med 2000;342:19461952.

87 Kohne CH, De Greve J, Hartmann JT, Lang I, Vergauwe P, Becker K, Braumann D, Joosens E, Muller L, Janssens J, Bokemeyer C, Reimer P, Link H, SpathSchwalbe E, Wilke HJ, Bleiberg H, Van Den Brande J, Debois M, Bethe U, Van Cutsem E: Irinotecan combined with infusional 5-fluorouracil/folinic acid or capecitabine plus celecoxib or placebo in the first-line treatment of patients with metastatic colorectal cancer. EORTC study 40015. Ann Oncol 2008;19:920-926.

88 Stein U, Burock S, Herrmann P, Wendler I, Niederstrasser M, Wernecke KD, Schlag PM: Diagnostic and prognostic value of metastasis inducer S100A4 transcripts in plasma of colon, rectal, and gastric cancer patients. J Mol Diagn 2011;13:189-198.

89 Hansen MT, Forst B, Cremers N, Quagliata L, Ambartsumian N, Grum-Schwensen B, Klingelhofer J, AbdulAl A, Herrmann P, Osterland M, Stein U, Nielsen GH, Scherer PE, Lukanidin E, Sleeman JP, Grigorian M: A link between inflammation and metastasis: serum amyloid A1 and A3 induce metastasis, and are targets of metastasis-inducing S100A4. Oncogene 2015;34:424435.

90 Ling Z, Li R: Clinicopathological and prognostic value of S100A4 expression in gastric cancer: a meta-analysis. Int J Biol Markers 2014;29:e99-e111.

91 Liu Y, Tang W, Wang J, Xie L, Li T, He Y, Qin X, Li S: Clinicopathological and prognostic significance of S100A4 overexpression in colorectal cancer: a metaanalysis. Diagn Pathol 2013;8:181.

92 Boye K, Maelandsmo GM: S100A4 and metastasis: a small actor playing many roles. Am J Pathol 2010;176: 528-535.

93 Li Z-H, Bresnick AR: The S100A4 metastasis factor regulates cellular motility via a direct interaction with myosin-IIA. Cancer Res 2006;66:5173-5180.

94 Jia W, Gao XJ, Zhang ZD, Yang ZX, Zhang G: S100A4 silencing suppresses proliferation, angiogenesis and invasion of thyroid cancer cells through downregulation of MMP-9 and VEGF. Eur Rev Med Pharmacol Sci 2013;17:1495-1508.

95 Wang L, Wang X, Liang Y, Diao X, Chen Q: S100A4 promotes invasion and angiogenesis in breast cancer MDA-MB-231 cells by upregulating matrix metalloproteinase-13. Acta Biochim Pol 2012;59:593-598.
96 Che P, Yang Y, Han X, Hu M, Sellers JC, LondonoJoshi AI, Cai GQ, Buchsbaum DJ, Christein JD, Tang Q, Chen D, Li Q, Grizzle WE, Lu YY, Ding Q: S100A4 promotes pancreatic cancer progression through a dual signaling pathway mediated by SRC and focal adhesion kinase. Sci Rep 2015;5:8453.

97 Chen X, Luther G, Zhang W, Nan G, Wagner ER, Liao Z, Wu N, Zhang H, Wang N, Wen S, He Y, Deng F, Zhang J, Wu D, Zhang B, Haydon RC, Zhou L, Luu $\mathrm{HH}, \mathrm{He}$ TC: The E-F hand calcium-binding protein S100A4 regulates the proliferation, survival and differentiation potential of human osteosarcoma cells. Cell Physiol Biochem 2013;32:1083-1096.

98 Hua J, Chen D, Fu H, Zhang R, Shen W, Liu S, Sun K, Sun X: Short hairpin RNA-mediated inhibition of S100A4 promotes apoptosis and suppresses proliferation of BGC823 gastric cancer cells in vitro and in vivo. Cancer Lett 2010;292:41-47.

99 Orre LM, Panizza E, Kaminskyy VO, Vernet E, Graslund T, Zhivotovsky B, Lehtio J: S100A4 interacts with p53 in the nucleus and promotes p53 degradation. Oncogene 2013;32:5531-5540.

100 Goel HL, Mercurio AM: VEGF targets the tumour cell. Nat Rev Cancer 2013;13:871-882.

101 Prud'homme GJ, Glinka Y: Neuropilins are multifunctional coreceptors involved in tumor initiation, growth, metastasis and immunity. Oncotarget 2012;3:921-939.

102 Kroll J, Waltenberger J: VEGF-A induces expression of eNOS and iNOS in endothelial cells via VEGF receptor-2 (KDR). Biochem Biophys Res Commun 1998; 252:743-746.

103 Chen XL, Nam JO, Jean C, Lawson C, Walsh CT, Goka E, Lim ST, Tomar A, Tancioni I, Uryu S, Guan JL, Acevedo LM, Weis SM, Cheresh DA, Schlaepfer DD: VEGF-induced vascular permeability is mediated by FAK. Dev Cell 2012;22:146-157.

104 Rousseau S, Houle F, Landry J, Huot J: p38 MAP kinase activation by vascular endothelial growth factor mediates actin reorganization and cell migration in human endothelial cells. Oncogene 1997;15:2169-2177.

105 Wanami LS, Chen HY, Peiro S, Garcia de Herreros A Bachelder RE: Vascular endothelial growth factor-A stimulates Snail expression in breast tumor cells: implications for tumor progression. Exp Cell Res 2008; 314:2448-2453.

106 Stacker SA, Caesar C, Baldwin ME, Thornton GE, Williams RA, Prevo R, Jackson DG, Nishikawa S, Kubo H, Achen MG: VEGF-D promotes the metastatic spread of tumor cells via the lymphatics. Nat Med 2001;7: 186-191.

107 Zhao YC, Ni XJ, Li Y, Dai M, Yuan ZX, Zhu YY, Luo CY: Peritumoral lymphangiogenesis induced by vascular endothelial growth factor $\mathrm{C}$ and $\mathrm{D}$ promotes lymph node metastasis in breast cancer patients. World J Surg Oncol 2012;10:165.

108 Achen MG, Stacker SA: Molecular control of lymphatic metastasis. Ann N Y Acad Sci 2008; 1131:225234

109 Ribatti D: Tumor refractoriness to anti-VEGF therapy. Oncotarget 2016;7:46668-46677.

110 De Mingo Pulido A, Ruffell B: Chapter five - immune regulation of the metastatic process: implications for therapy; in Danny RW, Paul BF (eds): Advances in Cancer Research. Cambridge, MA, Elsevier, Academic Press, 2016, vol 132, pp 139-163.

111 Topalian SL, Drake CG, Pardoll DM: Immune checkpoint blockade: a common denominator approach to cancer therapy. Cancer Cell 2015;27:450-461.

$112 \mathrm{Ma}$ L: Chapter six - microRNA and metastasis; in Danny RW, Paul BF (eds): Advances in Cancer Research. Cambridge, MA, Elsevier, Academic Press, 2016, vol 132, pp 165-207. 